\title{
Theory and Research Concerning Social Comparisons of Personal Attributes
}

\author{
Joanne V. Wood \\ State University of New York at Stony Brook
}

\begin{abstract}
Social comparison theory has evolved considerably since Festinger (1954) originally proposed it. This article integrates these changes with insights offered by recent social comparison studies and by research on social cognition and the self. Contrary to the original theory or subsequent research, (a) the individual is not always an unbiased self-evaluator but may seek many goals through social comparison; (b) the social environment may not be inactive but may impose unwanted comparisons; and (c) the comparison process involves more than selecting a comparison target: It is bidirectional, rather than unidirectional, and it may adopt a variety of forms to meet the individual's goals. Research involving comparisons of personal attributes illustrates these principles.
\end{abstract}

The couples we knew were also aging . . . and paid rising taxes and suffered automobile accidents and midnight illnesses and marital woe; but under the tireless supervision of gossip all misfortunes were compared, and confessed, and revealed as relative. (Updike, 1985, p. 48)

Salieri, speaking of Mozart, in Amadeus:

Tonight . . . stands a giggling child who can put on paper, without actually setting down his billiard cue, casual notes which turn my most considered ones into lifeless scratches . . . [That] ensured that I would know myself forever mediocre. (Shaffer, 1980, p. 61)

An important source of knowledge about oneself is comparisons with other people. In 1954, Festinger proposed a theory of social comparison based on this insight. Although interest in the theory has waxed and waned since then (Goethals, 1986b), social comparison research has enjoyed a resurgence recently: Over 100 journal articles on social comparison have appeared since 1982, which is almost three times the number published in the theory's first 12 years (Radloff \& Bard, 1966). Moreover, social comparison processes are central to other prominent theories in social psychology, including relative deprivation (Masters \& Smith, 1987; Olson, Herman. \& Zanna, 1986), Tesser's self-evaluation maintenance model (Tesser, 1986), and Tajfel and Turner's (1979) social identity theory of groups. Although social comparison theory was once dubbed "everybody's second-favorite theory in social psychology (but almost nobody's first)" (Arrowood, 1978, p. 491), the literature has never before had more vitality.

These developments call for a reexamination of social comparison theory. For some time, researchers have operated under an understanding of social comparison that goes beyond Festinger's (1954) original theory and that in some ways contradicts

The author is grateful to several people who provided very helpful critiques of previous drafts of this article: Becky Collins, Jenny Crocker, Ron Friend, Marci Lobel, Brenda Major, John Michela, Judy Saltzberg, Kate Taylor, Shelley Tayior, Tom Wills, and Mark Zanna.

Correspondence concerning this article should be addressed to Joanne Wood, who is now at the Department of Psychology, University of Waterloo, Waterloo, Ontario, Canada N2L 361. it. However, various theoretical strands that have emerged in the past have not been woven together. In addition, past theoretical statements have not accommodated the insights that are offered by social comparison studies that have appeared in recent years or by research on social cognition and the self. This article integrates these older and newer insights. Together, they present a view of the social comparer and of the social environment that contrasts with that depicted by the original theory. Specifically, the individual harbors goals other than accurate self-evaluation, and the social environment is not always obliging. In addition, to achieve the individual's goals in the face of an unyielding environment, the comparison process must be more multifaceted and malleable than has been recognized previously.

This literature review illustrates this contrasting portrait of the individual, the social environment, and the comparison process, and focuses on comparisons of personal attributes such as abilities and personality characteristics. It does not concern comparisons of opinions, emotions, or comparison processes in groups. Although this article does not summarize relative deprivation research, which concerns comparisons of outcomes (e.g., pay), it does describe findings that are especially relevant to comparisons of personal attributes.

\section{Original Theory}

Festinger's (1954) social comparison theory postulates that humans have a drive to evaluate their opinions and abilities. To function effectively, they need to know their own capacities and limitations, and they must be accurate in their opinions of objects and of other people (Jones \& Gerard, 1967). Festinger thought that people best serve this need for self-evaluation by measuring their attributes against direct, physical standards. When objective standards are unavailable, however, individuals compare themselves with other people. The central proposition of Festinger's theory is the "similarity hypothesis," which predicts that individuals prefer to compare themselves with similar others. When individuals attempt to evaluate an ability and their performance is very different from that of other people, all that they can be certain of is that their own performance is 
unique. They cannot appraise their abilities precisely or assess how stable their abilities are. Festinger provided the example of novice chess players, who could not determine their skill precisely by comparing their games with those of master players.

Festinger also hypothesized a "unidirectional drive upward" that operates for abilities. In Western culture, people not only wish to evaluate their abilities, they also feel pressure to continually improve them. When combined with the desire to compare with similar others, this drive upward leads the individual to strive toward a point slightly better than that of comparison others.

In addition to these hypotheses, Festinger offered a number of provocative and testable derivations and devoted a substantial portion of his theory to outlining their implications for interpersonal processes. For example, the need for social comparison leads to affiliation, the need for similar comparison others leads to pressures toward uniformity in groups, and the unidirectional drive upward leads to competition.

Attesting to the richness and utility of Festinger's theory is the fact that it inspires active research more than three decades later. However, the theory has not kept pace with other developments in social psychology within that time period. In particular, research challenges the original theory's view of the individual and of the social environment.

\section{Are People Unbiased Self-Evaluators?}

Festinger emphasized accurate self-evaluation as the purpose of social comparison. Indeed, "the holding of incorrect opinions and/or inaccurate appraisals of one's abilities can be punishing or even fatal in many situations" (Festinger, 1954, p. 117). Festinger characterized the individual as largely rational and unbiased, as seeking a "stable," "precise," and "accurate" self-evaluation.

Festinger did suggest, however, that people may not be entirely unbiased. He implied that opinion evaluation is not an uninvolving process, in that individuals want their opinions to be "correct." Festinger (1954) also noted that when an ability is particularly low, "deep experiences of failure and feelings of inadequacy" are "not . . . unusual" (p. 137). However, Festinger did not specify how such feelings and motives may influence one's comparisons. Rather, his emphasis on the evenhanded, self-evaluative goals of social comparison and the unidirectional drive upward portrayed the social comparer as facing up to his or her honest self-assessment and perhaps as aiming to better the self. Are individuals really so rational and unbiased as this portrait suggests? Both classic and recent research in social psychology indicates that people harbor a variety of motives that pertain to the self, which may be grouped into three broad classes: self-evaluation, self-improvement, and self-enhancement.

Self-evaluation. Festinger's view is consistent with a dominant theme in social psychology-as reflected, for example, in attribution theory-that people strive to be accurate in their views of the world. Although researchers find it difficult to avoid confounding self-evaluation and self-enhancement concerns, many agree that individuals are interested in accurate self-evaluation (Raynor \& McFarlin, 1986; Trope, 1986). In Trope's (1986) research, for example, subjects are presented with a choice among tasks that vary in their capacity to diagnose levels of ability. Subjects tend to select tasks that will diagnose their abilities, and they often do so even when the outcome is likely to be unfavorable (see Trope, 1986, for a review). Other studies indicate that people are interested specifically in social comparison for self-evaluation (e.g., Scheier \& Carver, 1983).

Self-improvement. Individuals also strive to improve themselves. This interest has been well-documented in research on achievement motivation (Atkinson \& Raynor, 1974) and observational learning (Bandura, 1986). Self-improvement interests also are clearly visible in everyday life, in which "how-to" books and pop therapies serve a seemingly unquenchable public thirst. Although Festinger's unidirectional drive upward recognized individuals' interest in self-improvement, few studies have examined its role in social comparison.

Self-enhancement. An increasingly dominant theme in social psychology runs counter to Festinger's emphasis on accurate self-evaluation. There is growing evidence that people are not unbiased; they often harbor unrealistically positive views of themselves and bias information in a self-serving manner (e.g., Sackeim, 1983; Taylor \& Brown, 1988). This evidence attests to self-enhancement motives, motives aimed at protecting or enhancing one's self-esteem. Social comparisons clearly may arouse self-enhancement concerns. People do not accept all comparative information with aplomb; learning that a rival has won an award or a lover's heart may be painful indeed. Individuals may, in turn, make comparisons so as to improve their selfesteem.

Although the social comparison literature has long recognized that self-evaluation is not the only motive behind social comparison, it has not appreciated fully the implications that a complexly motivated social comparer has for the process of comparison. This article considers the ways in which the goals of self-evaluation, self-improvement, and self-enhancement affect the comparison process.

\section{Is the Social Environment an Inactive Backdrop in Social Comparison?}

Social comparison theory emphasized the individual as the "causal agent . . . standing out against a rather non-problematic environment" (Guiot, 1978, p. 30) and largely implied that the social environment is fairly passive toward and cooperative with the individual's aims. Festinger (1954) emphasized the individual's comparison interests and choices and gave little attention to situations in which the environment imposes comparisons on the individual. ${ }^{1}$

Moreover, the traditional social comparison literature has reflected this emphasis. Most studies conducted in the name of social comparison have asked, "Whom do subjects select for comparison?" rather than "What are the effects of comparisons on the subject?" (cf. Suls, 1986b). By emphasizing the individual's ability to select comparisons, the literature has largely reflected the view that the social environment is in the back-

\footnotetext{
' Festinger (1954) acknowledged that comparisons may be forced under two conditions: when a group member is strongly attracted to the group and when he or she is restrained from leaving the group.
} 
ground, waiting and cooperative. However, two areas of research that would not be included in the traditional social comparison literature have concerned the effects of comparisons, and these areas portray a very active role for the social environment.

Effects of comparisons on self-concept. In several studies, researchers have related some aspect of subjects' social environment to their self-evaluations. If they are related, this suggests that the social environment has provided comparisons that have shaped the subjects' self-evaluations. For example, Marsh and Parker (1984) related the average ability level in children's schools with the children's self-esteem and found that if children are surrounded by others with higher ability, their selfesteem tends to be lower than if they are surrounded by others of lower ability (but see Bachman \& O'Malley, 1986). Similarly, college graduates' relative standing among their peers is a critical predictor of their career aspirations (Davis, 1966). A student who earns high grades at a college where it is easy to earn high grades tends to have higher career aspirations than an equally qualified student at a more competitive college. This phenomenon has been called

\section{"the campus as a frog pond"; for the frog in a shallow pond aims his sights higher than an equally talented frog in a deep pond. (Petti- grew, 1967, p. 257)}

The degree to which individuals define themselves in relation to others in their social environment, rather than on the basis of objective criteria, is quite striking (see 'Marsh \& Parker, 1984; Pettigrew, 1967; and Ruble, 1983; for references). For example, Harter (1985) found that mainstreamed mentally retarded (with IQs of 50 to 70) children's perceptions of their scholastic competence were equal to those of normal children, whereas mainstreamed learning-disabled (with normal IQs) children's perceptions of their competence were lower than those of normal children. This paradoxical finding was explained by Harter's (1985)'discovery that the mainstreamed retarded children were comparing themselves with their retarded peers, whereas the mainstreamed learning-disabled children were comparing themselves with normal children (see also Gibbons, 1985; Strang, Smith, \& Rogers, 1978).

In addition to these effects of social comparisons on global aspects of self-evaluation, one's feelings about the self may ebb and flow with situational variations in one's social context. In Morse and Gergen's (1970) classic "Mr. Clean/Mr. Dirty" study, for example, college students' self-esteem suffered when they applied for a job in the presence of a fellow applicant who looked very clean and competent. They felt better when the fellow applicant was unkempt and disorganized. Also illustrative is McGuire's research, which suggests that whatever aspect of oneself is distinctive in relation to other people in any particular setting is prominent in one's thoughts about the self. For example, sixth graders who were asked to describe themselves were more likely to mention their hair color when their hair was red or blond than when it was dark, which is more common (McGuire \& Padawer-Singer, 1976). The self-concept is responsive, then, to changes in the social context, which again suggests that the social environment imposes comparisons that have an impact on the individual.

Effects of comparisons involving personal outcomes. Sim- ilarly, relative deprivation research indicates that whether one is satisfied or dissatisfied with one's outcomes often has less to do with the absolute level of those outcomes than with the standards that are salient in one's social setting. For example, 10year corporate executives who are making more money than they ever dreamed of may nonetheless be resentful if they learn that a new employee's salary is higher than their own (Messé \& Watts, 1983):-The relative deprivation literature is replete with examples of poor and downtrodden people who are not dissatisfied and of affluent, seemingly fortunate people who are (Crosby, 1976; Olson et al., 1986). Similarly, one's satisfaction with life appears to depend less on objective circumstances than on how one stands in relation to others; if one is better off, one is happy (see Diener, 1984, for a review).

Studies that have focused on self-concept and on feelings of satisfaction about personal outcomes, then, suggest that the social environment provides comparisons that impinge on the individual, whether or not he or she has "selected" them. These studies challenge, Festinger's (1954) implicit depiction of the social environment as an inactive backdrop for the individual's comparisons. At the same time, this research clearly and strongly supports the basic thrust of Festinger's theory: People compare themselves with other people, and their comparisons are pivotal to their self-evaluations.

If researchers begin to focus more on the effects of comparisons, they are likely to discover that social comparison is pervasive and powerful in everyday life. Comparisons need not involve explicitly evaluative situations (such as test taking) or salient comparison referents (such as when a coworker gets a promotion). Social comparison may occur automatically; it may be an "almost inevitable element of social interaction" (Brickman \& Bulman, 1977, p. 150). One may read about comparison others in the newspaper or see them on the street (e.g., "Is that Porsche driver really happier than I am?"). Such comparisons may affect one's self-evaluation, even though one has not selected them (Allen \& Wilder, 1977; Guiot, 1978).

\section{Serving Goals Through Social Comparison}

If the individual has goals other than accurate self-evaluation, and if the environment imposes comparisons on the individual, what are the implications for the process of social comparison? Several implications are illustrated by the research reviewed herein. One implication of an active social environment is that the comparison process is not one way, emanating from the individual toward the environment, but two way, and hence individuals' reactions to comparisons are a critical component of comparison processes. Accordingly, in this review, studies of people's reactions to comparisons are presented whenever possible and determinants of those reactions are identified.

The individual's goals also have considerable influence on the comparison process. Festinger's (1954) emphasis on self-evaluation led to a single prediction regarding whom people will select for comparison: similar others. However, a similar comparison other may not be the comparison target of choice under all comparison goals. For example, self-improvement interests may prompt one to make comparisons with others who are superior or better off in some way; these are called upward com- 
parisons (Wheeler, 1966). ${ }^{2}$ Self-enhancement interests may prompt one to make comparisons with others who are inferior or less fortunate than oneself; these are called downward comparisons (Wills, 1981).

Although this review identifies ways in which the individual's goals direct the choice of comparison target, it becomes clear that the literature has overemphasized target selection. Selecting a target is not the only comparison strategy that individuals have at their disposal. Research on social cognition and the self suggests that people may interpret, distort, and ignore information so as to see themselves positively (see Taylor \& Brown, 1988 , for a review). To integrate the implications of this evidence for social comparison, this article considers the ways in which individuals may exert influence on the comparison process in order to achieve their goals. In the face of a sometimes unyielding environment, the comparison process may adopt a variety of forms other than target selection.

Another sense in which research has overemphasized the comparison target is that it has failed to appreciate the role of two other components of the comparison process: (a) the nature of the dimension under evaluation and (b) the dimensions that surround the dimension under evaluation. The dimension under evaluation is the attribute-such as shyness, beauty, or productivity - on which one is making a comparison. The nature of the dimension under evaluation varies in important ways, such as in how familiar it is and how personally important it is, and these variations have critical consequences for comparison processes.

Surrounding dimensions are dimensions that are involved in comparisons but are not the focal dimension under evaluation. For example, if one is evaluating one's ability to play the piano, one may not only compare one's own piano playing with that of others' piano playing; one also may take into account dimensions other than piano playing, such as how long the other person has played and whether the other is a professional or a hobbyist. Although research largely has emphasized the comparisons that one makes along the single dimension that one is evaluating, comparisons along these surrounding dimensions are pivotal in comparison processes. Both the dimension under evaluation and these surrounding dimensions influence how individuals seek to satisfy their goals through social comparison, as well as how they react to comparisons that are imposed by the environment.

The research supporting this analysis is organized around the goals of self-evaluation, self-improvement, and self-enhancement. Within the section for each goal, I discuss the various ways in which comparisons may serve that goal and the ways in which the dimension under evaluation and the surrounding dimensions come into play.

The measures that have been used in social comparison research are introduced briefly here. They fall into four main categories. The rank-order paradigm, which focuses on subjects' comparison selections, is described shortly. Other selection measures include the time subjects spend observing others (e.g., Ruble, Feldman, \& Boggiano, 1976). Another category of measure looks at the effects of comparisons on such variables as subjects' performances and emotional responses (e.g., Carlson $\&$ Masters, 1986). Free-response measures monitor the comparisons that individuals express as they occur, such as the compar- isons that school children make in the classroom (e.g., "She's on 13 , and I'm only on 10"; Frey \& Ruble, 1985). On comparative rating measures, subjects rate themselves in relation to others on some dimension, such as creativity (e.g., Alicke, 1985). Another type of comparative rating is used in false-consensus studies, in which subjects are asked to predict the percentage of people who would have the same response as they and the percentage who would respond differently (see Marks \& Miller, 1987, for a review). ${ }^{3}$ Although these diverse operationalizations may reflect different meanings or facets of social comparison (Wood, 1989), all types are included in this review.

\section{Self-Evaluation}

How may social comparisons serve self-evaluative goals? First discussed is the vehicle that the literature emphasizes most.

\section{Target Selections Along the Dimension Under Evaluation}

\section{Festinger's similarity hypothesis reads as follows:}

The tendency to compare oneself with some other specific person decreases as the difference between his [or her] opinion or ability and one's own increases. (Festinger, 1954, p. 120)

This seemingly simple hypothesis sparked considerable debate over what constitutes a "similar" comparison other (Latané, 1966; Suls, 1977). According to one interpretation, the phrase "the tendency to compare . . . decreases as the difference . . . increases" implies that similarity is defined in terms of the specific dimension under evaluation. That is, when evaluating an ability, one would compare oneself to someone whose ability is similar to one's own. Evidence pertaining to this interpretation of similarity is considered first.

Rank-order studies are well suited to examining this interpretation of similarity, because they offer subjects a selection of comparison targets who vary only in their positions on the dimension under evaluation. Subjects are given bogus information about how they and several other subjects scored on a test. They are told that their score ranks in the middle of the others' scores and are given the opportunity to see the score of a person occupying one other rank. According to the similarity predic-

\footnotetext{
${ }^{2}$ Festinger (1954) did not specify precisely how the unidirectional drive upward would affect comparison selection (Dakin \& Arrowood, 1981 ; Suls, 1977). Many have interpreted it to mean that it would combine with interests in similarity to yield comparisons with others who were slightly superior to oneself (e.g., Wheeler, 1966). However, Hakmiller (1966a) predicted the opposite: that the drive upward would lead to downward comparisons, because one would prefer to see oneself as better than others.

${ }^{3}$ The degree to which consensus estimates reflect social comparisons is unclear (Marks \& Miller, 1987; Wood, 1989). Indeed, whereas social comparison is typically thought to involve using others as reference points to evaluate the self, false-consensus effects typically are thought to involve using the self as a reference point to make judgments about others (although Marks and Miller argue that frequently they may not involve even that). Because comparison researchers have used false-consensus methods, however, these methods are included here, and their implications for social comparison are discussed.
} 
tion, subjects will select comparison others who are close to themselves in the rank order. A large number of studies support this prediction (e.g., Gruder, 1971; Gruder, Korth, Dichtel, \& Glos, 1975; Wheeler, 1966; Wheeler, Koestner, \& Driver, 1982).

Unfamiliar versus familiar dimensions. However, Wheeler et al. (1969) discovered an important exception to the similarity prediction: When subjects do not know what the range of scores is, they prefer to learn the scores of the others who are most dissimilar to themselves in the rank order: the highest scoring person and the lowest scoring person (Friend \& Gilbert, 1973; Gruder, 1971; Gruder et al., 1975; Thornton \& Arrowood, 1966; Wilson \& Benner, 1971). If subjects already know what their scores are in the rank-order studies, and they know that their score falls in the middle of the group, what exactly are they doing when they seek information about the extremes? Extremely different others may exemplify the characteristic under evaluation, which may be particularly useful when one is unfamiliar with the dimension under evaluation (Arrowood \& Friend, 1969; Thornton \& Arrowood, 1966). For example, a young girl seeking to understand what extroversion is may look to an extremely outgoing friend and to an extremely timid friend.

Another possibility is that when people are unfamiliar with the dimension under evaluation, they first wish to determine the range of scores on the dimension (Deutsch \& Krauss, 1965; Singer, 1966; Wheeler et al., 1969). Learning the range of scores may be helpful because knowing one's own score may have little meaning by itself. Given the evidence cited earlier that people define themselves in relation to others in their social environment, subjects may not be able to interpret their own score without knowing where others stand on the dimension and how far the middle score is from those of the others. This interpretation of range seeking is consistent with evidence from studies that do not use the rank-order method. When subjects are not constrained to select a single score, they appear to be interested in obtaining any information they can about the dimension; they are interested in learning the group's mean (Sanders, 1982a; Suls \& Tesch, 1978) or in examining the entire distribution of scores (Brickman \& Berman, 1971), especially when they are uncertain about the dimension under evaluation (Brickman \& Berman, 1971; Gruder et al., 1975). These results suggest that on unfamiliar dimensions, or on previously familiar dimensions in a new social context, one's goal is to learn the distribution of others' standings, perhaps as an initial step toward self-evaluation (cf. Wheeler \& Zuckerman, 1977).

As individuals become more familiar with the distribution on the underlying dimension, their comparison choices change. Once subjects in rank-order studies know the range of scores, they choose to see the scores of others at similar ranks, presumably to see precisely how similar they are to these others (e.g., Wheeler et al., 1969). Similarly, Trope's (1979) studies suggest that when individuals evaluate an ability, they tend to choose tasks that are diagnostic of that ability within the range of their uncertainty. That is, a highly able person tends to choose a task that will discriminate between high-ability levels; a person low in ability chooses a task that will discriminate between low-ability levels. People also prefer to compete with others who have about the same level of ability (Dakin \& Arrowood, 1981; Gastorf, Suls, \& Lawhon, 1978; Hoffman, Festinger, \& Lawrence,
1954; R. L. Miller \& Suls, 1977). ${ }^{4}$ Although dissimilar others may be particularly informative when individuals are unfamiliar with the dimension under evaluation, the range of relevant comparison others appears to narrow as individuals become more aware of their own standing.

Moreover, studies of the effects of comparisons (rather than comparison selections) indicate that, as Festinger (1954) predicted, one's self-evaluation becomes more stable and accurate when one compares oneself with others whose abilities are similar (Radloff, 1966; Wilson, 1973; but see Gastorf \& Suls, 1978). Comparisons with others who are very different on the dimension under evaluation, on the other hand, appear to have very little impact (France-Kaatrude \& Smith, 1985; Mettee \& Smith, 1977; Sanders, 1982b). For example, subjects' performance on a task improved when they were in the presence of someone whose performance was slightly better, but their performance was not affected when the other's performance was highly discrepant from their own (Seta, 1982). When comparison others are too different, "one merely ceases to compare oneself with those persons" (Festinger, 1954, p. 128).

Selection of versus effects of dissimilar comparisons. These results point to an intriguing asymmetry between the selection of and the effects of comparisons with others who are dissimilar on the dimension under evaluation. Although people often seek information about others who are dissimilar, they appear to be little affected by comparisons with them. Individuals who are extremely different may help one to define the range of possibilities, but once one defines that range, those individuals may have little relevance to oneself. The relative deprivation literature describes a fascinating real-world illustration of this principle. $\mathbf{R i}$ ots and revolutions do not tend to occur when a group is extremely deprived in relation to other groups but only after the group's condition has reached a level closer to that of a privileged group (Pettigrew, 1967). Only then, apparently, is the other group similar enough to be relevant for comparison.

These findings regarding self-evaluative comparisons along the dimension under evaluation point to one way in which the nature of that dimension is influential. In this case, the nature of the dimension refers to its familiarity, which may assume importance because it elicits different motives. On unfamiliar dimensions, individuals appear to be motivated to learn more about the distribution of others' standings, and as they learn more, they appear to try to fine-tune their self-evaluation.

\section{Comparisons on Related Dimensions}

Because the first interpretation of similarity considers only one's relative position on the dimension under evaluation, that is the only information available about potential comparison others in most of the studies just reviewed. Although these stud-

\footnotetext{
${ }^{4}$ Under competitive conditions, similarity is confounded with likelihood of success, and hence these choices may reflect desires to win rather than desires to compare (Dakin \&.Arrowood, 1981). At the same time, however, subjects do not tend to prefer the easy wins that would be guaranteed by choosing competitors who are clearly inferior in ability (e.g., Gastorf et al., 1978). Thus, subjects' interests in social comparison may motivate their selection of similar others in the competition studies.
} 
ies reveal important processes concerning that dimension, one may ask, Do individuals typically confine their comparisons to the specific dimension under evaluation when they seek selfevaluation?

According to a second interpretation of similarity, they do not. Several researchers have argued that people make more informative comparisons by also considering dimensions that are related to the dimension under evaluation (see Suls \& Miller, 1977). To paraphrase an example offered by Zanna, Goethals, and Hill (1975), a swimmer evaluating his or her swimming speed would consider not only other swimmers' swimming speed (the dimension under evaluation) but also their age, experience, and recent practice (dimensions related to swimming speed) when selecting someone for comparison. Rather than compare him or herself with someone whose speed was similar, the swimmer would compare him or herself with someone who was similar on those related dimensions. Similarly, Festinger (1954) himself suggested that if another person's ability was very different from one's own, and if that person was "perceived as different from oneself on attributes consistent with the divergence" (p. 133), one would stop comparing oneself with that person.

The debate over the two interpretations of similarity had centered largely on attempts to discern "what Festinger meant" (a frequently used phrase in the social comparison literature), until Goethals and Darley's (1977) attributional analysis of social comparison brought the importance of related dimensions into clearer conceptual focus. Goethals and Darley (1977) reasoned that ability evaluation involves inferring one's own and another's ability from relative performance. However, that inference is imperfect, because performance is determined not by ability alone but also by such factors as effort and practice. When one compares oneself to another who is different from oneself on these dimensions, the attribution regarding ability is ambiguous. For example, if novice swimmers compare their swimming speeds with those of Olympic champions, they cannot be sure whether their slower speed stems from lower innate ability or from fewer years of practice. Goethals and Darley (1977) therefore predicted that individuals would compare themselves with others who were similar in terms of characteristics "related to and predictive of performance" (p. 265). This interpretation of similarity is referred to as related-attributes similarity (Wheeler \& Zuckerman, 1977).

The related-attributes hypothesis has received a great deal of support. When subjects have the opportunity to consider attributes that are related to the dimension under evaluation, they prefer to compare themselves with others who are similar on those dimensions (Suls, Gastorf, \& Lawhon, 1978; Zanna et al., 1975; see especially C. T. Miller, 1982; Wheeler et al., 1982). Moreover, people who already have information about their relative standing on the dimension under evaluation still desire information about related attributes (Wheeler \& Koestner, 1984).

Related attributes are critical to both sides of the comparison process: the individual and the social environment. Related attributes are useful in serving the goal of self-evaluation because, by reducing attributional ambiguity, they permit one to better understand the meaning or implications of one's standing on the dimension under evaluation. Related attributes also influence one's reactions to comparisons that are imposed by the envi- ronment. An example comes from relative deprivation research, which suggests that people are most resentful about not having something when similar others have it (see Crosby, 1976, for a review). For example, "the wages of manual workers are more important in determining whether or not miners feel entitled to a pay increase than are the salaries of white-collar workers" (Crosby, 1976, p. 95). Thus, comparisons with others who are similar on related attributes appear to have more impact than comparisons with others who are dissimilar (see also Gastorf \& Suls, 1978; Sanders, Gastorf, \& Mullen, 1979).

This evidence regarding related attributes points more generally to the importance of the dimensions that surround the dimension under evaluation. Related attributes refer specifically to those surrounding dimensions that predict performance on the focal dimension. However, the term surrounding dimensions refers more loosely to any dimension other than the specific dimension under evaluation. Surrounding dimensions cannot be defined more precisely at this time because, as is discussed next, it is not always clear what makes a surrounding dimension relevant.

\section{Must Surrounding Dimensions be Related to be Relevant?}

The hypothesis that people prefer to compare themselves with others who are similar on characteristics that are "related to and predictive of performance" (Goethals \& Darley, 1977, $\mathbf{p}$. 265 ) implies that similarity on surrounding attributes should not be important if those attributes are not related to the dimension under evaluation (Gruder, 1977). But that does not appear to be the case. Although people are interested in comparing themselves with others who are similar on related attributes, they also frequently select similar others for comparison regardless of whether the basis of the similarity is relevant to the dimension under evaluation (Feldman \& Ruble, 1981; C. T. Miller, 1982; D. T. Miller, Turnbull, \& McFarland, 1988; Samuel, 1973; Suls, Gaes, \& Gastorf, 1979). An example is a study in which the dimension under evaluation was logical reasoning. The subjects chose to compare themselves with others who were similar in physical attractiveness, even though attractiveness was perceived to be unrelated to logical reasoning (C. T. Miller, 1982). Similarly, Major and Forcey (1985) provided subjects with an opportunity to compare their wages with those of the average man, those of the average woman, and the average wage combined across sex for tasks they had completed. Not surprisingly, most subjects preferred to receive information about the wages of others who had performed the same task, clearly a related attribute, but they also chose to compare themselves with others of the same sex, even when the job was unrelated to gender and even though they could have compared their wage with the average combined-sex wage.

Moreover, comparisons with similar persons seem to have more impact than comparisons with dissimilar persons even when the similarity seems to be unrelated to the dimension under evaluation. For example, helping situations prompt social comparisons that often imply to the recipient that he or she is inferior to the helper (Brickman \& Bulman, 1977). Studies have suggested that the recipient's self-esteem suffers more when the helper and recipient are similar rather than dissimilar (see 
Fisher, Nadler, \& Whitcher-Alagna, 1982, for references). For example, after subjects lost heavily in a stock market simulation, they felt worse about themselves when they received aid from someone who was similar, even though the similarity dimension, attitudes on several topics, seems to have been unrelated to skill in investing (Nadler, Fisher, \& Streufert, 1976).

Especially revealing is a series of studies by Tesser, Campbell, and their colleagues (see Tesser, 1986, for a review). These studies indicate that comparisons with others who are similar on any of several dimensions-such as age, sex, race, college major, and personality-have more impact on one's affect and self-esteem than do comparisons with dissimilar others. Tesser (1986) conceptualizes similarity in terms of closeness, which is

similar to Heider's (1958) notion of a unit relation. . . . Closeness increases with similarity, physical proximity, family ties, similarity in place of origin, and the like. (p. 438)

Although in some of Tesser's studies closeness involves similarity on a dimension that subjects may consider to be related to the dimension under evaluation, often the similarity seems to be unrelated. For example, Tesser and Campbell (1985) found that seniors in high school planned to continue their schooling if their grades were high in relation to the grades of others of the same sex and race, but their plans were unaffected by how they compared with others who were dissimilar in sex and race. Because grades are dependent on one's academic standing in relation to the standing of all others, it is unclear why sex and race would be so important to one's evaluation of one's ability in school. As another example, comparisons regarding social popularity, skills, and appearance have more impact when they are with siblings who are close in age than with siblings who are distant in age (Tesser, 1980).

Neither Festinger's (1954) original theory nor statements regarding related attributes anticipated the importance of similarity on unrelated attributes. Why is a comparison with a similar other especially potent, even when the basis of similarity should bear no implication for one's standing on the dimension under evaluation? This question is important because, if even unrelated attributes are critical, that suggests that little is known, after all, about whom people choose to compare themselves with and why (C. T. Miller, 1982).

"Correlated" attributes. One possible explanation as to why individuals may compare themselves with others who are similar on some unrelated dimension is because that dimension has been related to a host of comparison domains in the past (C. T. Miller, 1982; Suls et al., 1979). People frequently may make same-sex comparisons because gender is related, or is believed to be related, to a wide variety of domains, including physical, intellectual, occupational, and personality domains. A person simply may not stop to consider the relevance of gender to the current dimension under evaluation and may make same-sex comparisons out of habit (C. T. Miller, 1982).

The correlated-attributes idea is a plausible explanation for comparisons on such key dimensions as sex, but it does not seem capable of accounting for all of the unrelated dimensions that have been shown to be important. It seems unlikely, for example, that such dimensions as attendance at the same college (Samuel, 1973) or undergraduate major (Zanna et al., 1975 ) would be related to a large variety of domains in subjects' past comparisons. Another problem is that the correlated-attributes idea implies that people approach their comparisons mindlessly, which seems possible in the case of selecting comparisons but seems inconsistent with the strong impact that these seemingly irrelevant comparisons often have on affect and self-esteem.

Competitor comparisons. A related explanation for individuals' interest in similar others, even when the similarity seems irrelevant, is that such others may be their competitors (Suls et al., 1979). For example, because one competes for grades with others who have the same major, those others may be salient targets of comparison even on dimensions that seem irrelevant to grades. Moreover, many people have had the experience that seemingly unrelated dimensions are important in competitive circumstances. A more physically attractive but less qualified person may have received an award that one has hoped for, even though physical attractiveness was not related to the award criteria. However, several examples of subjects' interest in similar others do not seem to involve competitors. Why would individuals feel especially competitive with others who are similar in physical attractiveness (C. T. Miller, 1982) or in attitudes (Nadler et al., 1976)? This explanation also encounters the difficulty of specifying what constitutes a competitor. If people of the same sex or same race are one's competitors, what makes them so?

Self-defining comparisons. C. T. Miller (1984) offered the intriguing hypothesis that individuals prefer comparisons with others who are similar on dimensions that are central to their self-definition (cf. Suls et al., 1979; Wheeler \& Zuckerman, 1977). She found that individuals who were self-schematic (Markus, 1977) with respect to gender made same-sex comparisons regardless of the relevance of gender to the dimension under evaluation. However, people who were aschematic for gender made comparisons that supported the related-attributes hypothesis: They selected others who were similar in attributes related to the dimension under evaluation.

These results suggest that the two groups had different comparison goals. The aschematics appeared to be interested in the dimension provided by the investigator, because they selected comparisons that would make their relative standing on that dimension more meaningful. The gender schematics, however, seemed to be interested in that dimension only to the extent that it provided information about the gender dimension. $C$. T. Miller's (1984) findings warn social comparison researchers that subjects' motives for comparison may differ from those that the researcher expects: Their goal may not be to evaluate themselves on the dimension under evaluation as defined by the investigator, but to evaluate themselves on dimensions that are more central to their identities.

Comparison goals. A recent study by D. T. Miller et al. (1988) helps to clarify what constitutes a self-defining dimension and supports the view that different types of similarity serve different comparison goals. These investigators showed that individuals are especially interested in comparing themselves with others who are similar in some distinctive way. When subjects were given the choice of comparing themselves with one of two persons, both of whom were similar to the subject in a type of "perceptual style," they overwhelmingly chose to compare themselves with the one with whom they shared an 
unusual, rather than common, perceptual style. In addition, subjects appeared to view distinctive attributes as especially self-defining (cf. McGuire \& Padawer-Singer, 1976). D. T. Miller et al. (1988) argued that when people compare themselves with others with whom they share a distinctive attribute, that serves the purpose of "determining their standing relative to others with whom they identify or feel a bond" (p. 909), which is critical in evaluating their self-worth. In contrast, comparing themselves with others who are similar in related attributes serves the purpose of "determining their standing relative to other people in general" (D. T. Miller et al., 1988, p. 908), which is helpful when evaluating a specific attribute.

In addition to helping to define self-defining, D. T. Miller et al.'s research bridges this concept and another concept critical to unrelated similarity, namely, closeness. Tesser's (1986) closeness construct provides a unifying theme for all of the unrelated dimensions that have been found to be important: Other people of the same sex, age, college, occupation, and so forth are closer. Distinctiveness apparently contributes to closeness, in that subjects identified more closely with distinctively similar others than with nondistinctively similar others. An example may be that homosexual persons may tend to compare themselves with other homosexuals, whereas heterosexual persons, whose identity may revolve less around their sexual orientation, may not deliberately seek to compare themselves with other heterosexuals (D. T. Miller et al., 1988).

Although the view that different types of similarity serve different purposes is quite promising, further work such as that of D. T. Miller et al. (1988) is needed to identify the determinants of closeness and the purposes that different types of closeness serve. Some dimensions that are self-defining and on which closeness clearly matters are not very distinctive (e.g., sex). In addition, some dimensions seem to be neither distinctive nor self-defining for most individuals (e.g., some attitudes). Each of these possible explanations for the importance of unrelated similarity, then, appears to account for some instances of subjects' interest in unrelated similarity, but none appears to account for all of them. A fruitful approach for future researchers may be to address the questions these explanations leave unanswered, such as, What makes a similar other one's competitor? And what dimensions of closeness serve what purposes?

Although the evidence that unrelated similarity is important runs contrary to the related-attributes hypothesis, it nonetheless underscores the importance of dimensions that surround the dimension under evaluation. Indeed, that evidence widens the scope of the surrounding dimensions that may be relevant in any given comparison. It is clear that, like related attributes, other types of surrounding dimensions are important in serving comparison goals and in determining the impact of comparisons received from the environment.

It is surprising that presently, more than 10 years after Goethals and Darley's (1977) paper, researchers still often focus solely on the specific dimension under evaluation. This focus sometimes may lead to inaccurate conclusions about comparison priorities. Many rank-order studies, for example, suggest that people prefer to make upward comparisons, that is, to compare themselves with others whose scores are better than their own (e.g., Wheeler \& Koestner, 1984). However, when subjects are given information other than just relative performance on the specific dimension under evaluation, such as the others' sex or age, they prefer to compare themselves with others who are similar on these characteristics, as well as better in performance (Feldman \& Ruble, 1981; Wheeler et al., 1982). In fact, subjects' interest in others who are generally similar often outweighs their interest in better-performing others (Hoffman et al., 1954; Suls, Gastorf, \& Lawhon, 1978; Zanna et al., 1975). Studies that offer only a limited range of comparison options along a single dimension, then, may be misleading.

\section{Summary of How Social Comparisons May Serve Self-Evaluation}

When one is self-evaluating one may seek (a) to learn about an unfamiliar dimension, by comparing oneself with others who are extremely dissimilar on the dimension or with the entire distribution of scores; (b) to pinpoint one's own standing, by comparing oneself with others who are proximal on the dimension; and (c) to understand the meaning of one's standing on a specific dimension, by comparing oneself with others who are similar in related attributes. In addition, people choose to compare themselves with others who are similar on even unrelated surrounding dimensions, and the degree of similarity on surrounding dimensions determines the impact of comparisons that are presented by the environment. This evidence underscores the fact that the comparison target is not the only important element in comparison processes; individuals also consider the nature of the dimension under evaluation and the dimensions that surround the dimension under evaluation when drawing comparisons.

\section{Self-Improvement}

This section is shorter than the other two sections because very little research has been aimed at discovering the ways in which social comparisons may be used for self-improvement. Nonetheless, evidence does suggest that self-improvement interests prompt social comparisons. Young children, for example, often compare themselves with other children to learn how to perform tasks (Feldman \& Ruble, 1977).

\section{Target Selections Along the Dimension Under Evaluation}

Many researchers have viewed upward comparisons as reflecting Western culture's emphasis on achievement, or what Festinger (1954) called the unidirectional drive upward. Consistent with this view, there is evidence that both people who are highly motivated to achieve a goal (Wheeler, 1966) and Type A individuals, who are hard-driving and competitive (Gastorf, Suls, \& Sanders, 1980; Matthews \& Siegel, 1983), are especially likely to make upward comparisons.

Even primarily self-evaluative comparisons may be colored by self-improvement motives. As was noted earlier, many rankorder studies demonstrate that people tend to compare themselves with others whose scores are better than their own (Arrowood \& Friend, 1969; Friend \& Gilbert, 1973; Gruder, 1971; Samuel, 1973; Suls \& Tesch, 1978; Thornton \& Arrowood, 1966; Wheeler et al., 1969; Wheeler \& Koestner, 1984). When 
comparing themselves with the extremes of the dimension, their first choice is the most positive extreme rather than the most negative (e.g., Arrowood \& Friend, 1969), and even when they compare themselves with similar others, they compare themselves with those who are close but "above" them in the rank order rather than "below" them (e.g., Wheeler et al., 1969). Apparently, individuals are more interested in assessing how they stand in relation to superior others rather than to inferior others (Nósanchuk \& Erickson, 1985; Seta, 1982). If one measures oneself against these successful individuals, one's selfevaluative comparisons may ultimately lead to self-improvement. Upward comparisons also may serve self-improvement goals in other ways. One may watch others who are more skilled or accomplished, hoping to learn from them (Berger, 1977) or to be inspired by their example (Brickman \& Bulman, 1977).

\section{Comparisons on Surrounding Dimensions}

Modeling. Comparisons on dimensions that surround the dimension under evaluation may be pivotal in self-improvement efforts. The modeling literature indicates that people are most likely to imitate another person's behavior when that person is similar to themselves (see Bandura, 1986, for a review). Individuals also tend to adopt the performance standards of others who are similar on surrounding dimensions. For example, children appear to be more interested in comparing their performance on a new task with that of same-age peers than with that of adults or younger children and to decide which of their own performances deserves a reward on the basis of their peers' performances (W. P. Smith, Davidson, \& France, 1987).

Imitating others who are similar on dimensions that are related to the performance dimension makes sense, because one may draw inferences about one's own performance or one's potential. For example, an aspiring journalist may be encouraged by learning that a prominent journalist attended the same school of journalism. Once again, however, the similarity between the observer and the model may be important even when it occurs on a dimension that is objectively unrelated to the imitated dimension. For example, people with phobias who observe other people successfully cope with a feared stimulus are encouraged more when these others are similar rather than dissimilar in sex and age, even when sex and age "do not really affect how well one can perform the feared activities" (Bandura, 1986, p. 404).

Inspiring versus threatening upward comparisons. One risk of upward comparisons as a vehicle for self-improvement is that they may be demoralizing, because one is forced to face one's own inferiority. One's concerns for self-improvement may conflict with one's concerns for self-enhancement. What determines whether upward comparisons are inspiring or threatening? The answer again illustrates the significance of surrounding dimensions. Wheeler (1966) proposed that highly motivated persons, those most likely to make upward comparisons, are spared feelings of inferiority because they assume that they are similar to the highly performing other. One may fasten on the general dimensions on which one is similar to the other and infer that one day, one also will be successful on the specific dimension under evaluation. For example, a junior tennis pro- fessional making upward comparisons to Martina Navratilova is not likely to feel threatened, but inspired.

However, other research seems to contradict the idea that upward comparisons are inspiring if one assumes similarity to the superior other. Recall that upward comparisons may be particularly painful when the superior others are close or similar on surrounding dimensions. As another example of that phenomenon, women who saw pictures of physically attractive women rated their own physical attractiveness as relatively low, except when they thought that the attractive others were professional models (Cash, Cash, \& Butters, 1983). Subjects seem to have been able to dismiss the implied comparison of professional models (i.e., dissimilar others) but could not do so when they believed that the other was a peer (i.e., similar; see also Hoffman et al., 1954; Mettee \& Smith, 1977). Such results suggest that rather than being encouraging, upward but generally similar comparisons are particularly likely to wound one's self-esteem.

A resolution to this contradiction may rest on whether the similar other is a competitor (Brickman \& Bulman, 1977; Mettee \& Smith, 1977, 'but see Morse \& Gergen, 1970). Evidence suggests that when similar others are competitors, upward comparisons are aversive, but when they are not competitors, their superior performance is inspiring (or irrelevant; Brickman \& Bulman, 1977). Although Martina Navratilova's success is not likely to threaten the junior tennis professional, a fellow junior player's success is threatening. Under competitive conditions, people tend to avoid comparisons with superiors (Dakin \& Arrowood, 1981; R. L. Miller \& Suls, 1977; Van Knippenberg, Wilke, \& de Vries, 1981). ${ }^{5}$

Once again, then, surrounding dimensions are important both in serving one's comparison goal and in determining the impact of comparisons offered by the environment. Individuals seeking self-improvement may both learn from and feel encouraged by comparing themselves with others who are superior on the dimension under evaluation yet are similar on dimensions that are related to the evaluation dimension. The similarity on surrounding dimensions also influences the impact of any upward comparison; if the superior other is a competitor, for example, one may feel threatened.

\section{Self-Enhancement}

Clearly, when individuals attempt to achieve their goals through social comparison, they attend to more than just the comparison target. This is nowhere more true than in the case of self-enhancement, in which still more features of comparison emerge.

\section{Target Selections Along the Dimension Under Evaluation}

Upward versus downward comparisons. The preceding discussion of upward comparisons reveals that they may serve all

\footnotetext{
${ }^{5}$ If upward comparisons are aversive when the other is a competitor, the question then becomes, When will comparison circumstances be competitive? Apparently, they will be when they involve both close others and dimensions that are central to one's self-esteem (Pleban \& Tesser, 1981; Tesser \& Campbell, 1982). This property of the dimension under evaluation, its self-relevance, is discussed further in the section on self-enhancement.
} 
three comparison goals: One may evaluate oneself against the higher standard; one may learn from the superior other; and if one assumes similarity on surrounding dimensions, the upward comparison may be self-enhancing. However, a perhaps more reliable method of self-enhancement is to make downward comparisons. In a recent theoretical analysis, Wills (1981) reviewed a great deal of evidence suggesting that when people experience misfortune or threat, they frequently compare themselves with someone who is inferior or less advantaged.

For example, subjects who had been told that they were high in "hostility to one's parents" (which was described in very negative terms) overwhelmingly chose to compare themselves with others who had even more hostility than themselves (and in that sense were inferior and in the downward direction; Hakmiller, 1966b). Other experiments have indicated that threat leads to downward comparisons on both selection measures, in which subjects tend to select inferior comparison others (Friend \& Gilbert, 1973; Levine \& Green, 1984; Wilson \& Benner, 1971), and on comparative ratings, on which subjects tend to derogate others (Cialdini \& Richardson, 1980; Crocker, Thompson, McGraw, \& Ingerman, 1987). Moreover, downward comparisons appear to reduce distress or enhance self-esteem (Crocker \& Gallo, 1985; Gibbons, 1986; Hakmiller, 1966b; Lemyre \& Smith, 1985).

Downward comparisons also have been found in recent field studies. Individuals who had experienced job disruption (Pearlin, Lieberman, Menaghan, \& Mullan, 1981), marital conflict (Menaghan, 1982), spinal cord injuries (Schulz \& Decker, 1985), and general stressors (Pearlin \& Schooler, 1978) rated their circumstances as more favorable than those of others. In an interview study, the vast majority of breast cancer patients spontaneously compared themselves with others who were less fortunate than they (Wood, Taylor, \& Lichtman, 1985). For example, one woman said

I had just a comparatively small amount of surgery on the breast, and I was so miserable, because it was so painful. How awful it must be for women who have had a mastectomy. (Wood et al., 1985 , p. 1178)

Although these studies support the idea that threat prompts downward comparisons, recent evidence suggests that threat may not be a necessary prerequisite (Wood \& Taylor, in press); people may engage in self-enhancing downward comparisons even when not threatened.

Similar versus dissimilar comparisons. Another route to self-enhancement involves similar comparison others. Studies using comparative rating measures have indicated that when individuals have undesirable characteristics, such as difficulty making friends or strong fears, they tend to rate others as similar, that is, as also having these difficulties (Alicke, 1985; Campbell, 1986; Ross, Greene, \& House, 1977; Sherman, Presson, \& Chassin, 1984; Suls \& Wan, 1987). However, on desirable dimensions, people tend to rate themselves as superior to others and as unique in their superiority (Alicke, 1985; Brown, 1986; Campbell, 1986; Marks, 1984; Sanders \& Mullen, 1983). For example, when subjects say that they would engage in a desirable behavior such as donating blood, they estimate that few others would do the same, but when they say that they would act in an undesirable manner, such as not stopping to help an elderly couple change a flat tire, they estimate that most others would do likewise (Goethals, 1986a).

These differences between desirable and undesirable dimensions are consistent with an explanation that is motivational, namely, that subjects are seeking self-enhancement. However, it is not certain that subjects are using comparison processes to achieve self-enhancement. Comparative ratings are ambiguous as to what they reflect about social comparison (Wood, 1989). When subjects rate themselves in relation to others, they may try to mentally average all of the comparative information that they have received in the relevant domain, and hence their ratings may represent a summary of their past comparison experiences. However, ratings also may reflect individuals' current hopes about where they stand in relation to others more than the actual comparisons that they have made. Subjects who rate themselves favorably, for example, may be motivated to believe that others are inferior (Goethals, 1986a; Suls \& Wan, 1987).

Regardless of what these comparative rafing measures reflect about social comparison, they suggest that the nature of the dimension under evaluation may determine which comparison target will serve one's self-enhancement goals. On desirable dimensions, comparisons with dissimilar and, especially, inferior others will be most self-enhancing; on undesirable dimensions, one may feel better about one's own failings by focusing on others who are similarly flawed.

Self-relevance of the dimension under evaluation. The nature of the dimension under evaluation varies importantly in another way: its self-relevance. Festinger (1954) acknowledged that dimensions vary in their importance to the individual. $\mathrm{He}$ predicted that on important dimensions, one's self-evaluative drive will be particularly strong and that one will make comparisons within an especially narrow range of similar others. Contrary to Festinger's prediction, however, recent studies suggest that personally important dimensions arouse motives other than self-evaluation, as well as interest in comparison others . who are not similar.

These recent studies indicate that the nature of the dimension again is important in comparisons, both those presented by the environment and those made by the individual to serve his or her goals. The self-relevance of the dimension under evaluation may influence the effects of comparisons that the environment presents in two ways. First, comparisons along self-relevant dimensions appear to have more impact than comparisons that are not self-relevant. Children's feelings of self-worth appear to depend on how competent they believe they are in areas that they regard as important (Harter, 1986). In addition, Tesser's research suggests that a close other's success is particularly aversive when it involves a dimension that is central to one's selfdefinition (Pleban \& Tesser, 1981; Tesser \& Campbell, 1982; Tesser, Millar, \& Moore, 1988). Salovey and Rodin's (1984) study of "social-comparison jealousy" provides a good example: When business majors were told that their "business acumen" was "surprisingly low," they were likely to disparage the other and to feel anxious and depressed. When the dimension under evaluation is not dear to the self, however, one may enjoy a close other's accomplishments (Tesser, 1986). A physician may take pride in her brother the musician's success but may be distressed by her brother the physician's more successful career (Tesser, 1980). These studies also point to the second way in 
which self-relevance influences the effects of comparisons, namely, that dimensions that people cherish seem to be especially likely to awaken self-enhancement goals.

Self-relevance also determines in part how the individual attempts to satisfy self-enhancement goals. Tendencies to see oneself as superior and to underestimate others' talents are especially pronounced on dimensions that are self-relevant (Campbell, 1986; Marks, 1984), which suggests that people prefer to make downward comparisons on those dimensions. Indeed, sometimes people try to hinder the performance of others on self-relevant dimensions, thereby ensuring a downward comparison (Tesser \& Smith, 1980).

Self-relevance and social comparison research. Given the evidence that people experience discomfort when they compare themselves with others who are superior on self-relevant dimensions, it is surprising that the bulk of social comparison studies report preferences for upward or similar others. These studies may suggest that people are less motivated to avoid discomfort than to obtain accurate comparison information. Alternatively, most studies may have used dimensions that are not self-relevant and thereby may have omitted a feature of naturalistic comparison that influences comparison selection. Many studies have involved unfamiliar dimensions, either because bogus feedback may be more credible when it concerns unfamiliar dimensions or because self-evaluative interests may be strongest there. However, the picture that is painted by these studies appears to differ from the picture that emerges from studies using more familiar and consequential dimensions. When the dimension is self-relevant, people appear to be eager to see themselves as unique and superior, and their comparison preferences shift markedly to downward comparisons.

This argument may seem inconsistent with findings from several areas of social psychological research, such as conformity and interpersonal attraction, which suggest that often people strive to be like other people. However, these areas also may have concerned dimensions that typically are not self-relevant. False-consensus research, which has concerned many different types of dimensions, speaks well to this issue. Many false-consensus studies involve dimensions that are probably unimportant to most subjects' selfdefinitions, such as preferences for white or brown bread (Ross et al., 1977), or involve dimensions that are undesirable. On such dimensions, people typically say that others are similar to themselves, whereas on desirable or self-relevant dimensions, they do not tend to do so (e.g., Goethals, 1986a). At least in Western society, similarity on self-defining dimensions may imply that one is undistinguished or mediocre (Brickman \& Bulman, 1977; Fromkin, 1972). These false-consensus findings warn social comparison researchers that it is hazardous to generalize findings concerning unfamiliar or trivial dimensions to comparisons involving personally important dimensions.

In summary, many targets of comparison along the dimension under evaluation may serve self-enhancement goals. Which particular target-upward, downward, similar, or dissimilar-is most self-enhancing appears to depend on the nature of the dimension under evaluation, specifically, how desirable and how self-relevant it is.

\section{Comparisons on Surrounding Dimensions}

How are the dimensions that surround the dimension under evaluation important in self-enhancement? As was mentioned already, individuals may feel encouraged if a successful person is similar to themselves on related attributes, because they may infer that they, too, will become successful. Another strategy borrows similar attributional principles, but focuses on dissimilarity in related attributes. If a superior person is dissimilar to oneself on related attributes, one may attribute the other's superiority to those differences and thereby dismiss the comparison (Brickman \& Bulman, 1977). For example, breast cancer patients did not appear to feel inadequate in comparison with "supercopers," famous women whom the media present as adjusting extremely well to their breast cancer (Wood et al., 1985). Instead, the patients seemed to regard such comparisons as irrelevant. One respondent said, "They're very prominent women. They're very well-to-do. They're married. I could not relate to that" (Wood, Taylor, \& Lichtman, 1982, p. 7). By perceiving superior others as dissimilar, one may "take some of the sting out of defeat or inferiority" (Brickman \& Bulman, 1977, p. 162).

One even may try to create dissimilarity. Because individuals feel especially threatened when they are inferior to someone who is close, they may attempt to reduce closeness with the superior person (Tesser, 1986). One may spend less time with the other (Tesser, 1980), physically distance oneself (Pleban \& Tesser, 1981), or disparage the other (Salovey \& Rodin, 1984). By manipulating surrounding dimensions, either by focusing on dissimilarity in related attributes or by reducing closeness, one renders superior others as less relevant to one's self-esteem.

\section{Imagining Comparison Targets}

If no inferior comparison targets are readily available, one may imagine one. In the breast cancer study previously described, many respondents focused not on specific other women but on hypothetical others, in comparison with whom they were adjusting well (Taylor, Wood, \& Lichtman, 1983). For example, one woman said,

You read about a few who handle it well, but it still seems like the
majority really feel sorry for themselves. And I really don't think
they cope with it that well. I don't understand it, because it doesn't
bother me at all. (Taylor et al., 1983,p. 34)

Many respondents seemed to fabricate comparison others, or at best, to generalize from second-hand information about one or two people who had particular difficulty adjusting. By "manufacturing normative standards of adjustment," victims may emerge from comparisons as having adjusted very successfully (Taylor et al., 1983).

Several of the false-consensus findings mentioned earlier also may reflect the imagining of comparison targets. When individuals see themselves as uniquely superior on a valued dimension, or when they see their undesirable characteristics as common, they may be imagining a mass of comparison others who are inferior, or they may be projecting their undesirable characteristics onto others (Suls \& Wan, 1987).

\section{Avoiding Comparisons}

People also may aim for self-enhancement by avoiding rather than selecting comparison targets. Although this possibility has 
received little attention, people at times do appear to deliberately avoid social comparison (Brickman \& Bulman, 1977). When individuals believe that their ability is particularly low or they are otherwise threatened, they tend to avoid upward comparisons (Friend \& Gilbert, 1973; Gastorf et al., 1978; Pyszczynski, Greenberg, \& LaPrelle, 1985; Samuel, 1973; R. H. Smith \& Insko, 1987), and when they think that their inferiority will be made public, they are much less likely to interact with superior others (R. H. Smith \& Insko, 1987; Wheeler et al., 1969; Wilson \& Benner, 1971). Thus, one may forego the self-improvement benefits of upward comparisons in favor of preserving one's self-esteem.

But what if the person has no choice, if the environment imposes comparisons? For example, how can poor people restrict their comparisons to similar others, even when reminders of affluence are salient? Martin (1986) offered a striking illustration. When an Appalachian woman was asked by a friend about the amount of money she was earning, she replied,

\begin{abstract}
"I am very content; I have more than my neighbors." Her friend continued, "What about the people on "the hill'?" (This was a wealthy residential area, clearly visible from the [woman's] front yard.) She answered, "My life is here. I don't think about them." (Martin, 1986, p. 217)
\end{abstract}

Even forced comparisons, then, may be avoided cognitively.

\section{Selection of Comparison Dimensions}

The nature of the dimension under evaluation has been discussed in terms of how it determines the goal of comparison. However, the individual's goal may well determine which dimension he or she selects for comparison. Although this possibility seems intuitively obvious, the literature scarcely has recognized it (Taylor et al., 1983). Instead, most studies have provided subjects with a single comparison dimension on which they must draw a comparison. A few studies, however, do suggest that individuals may select particular dimensions on which to make comparisons.

Many respondents in the breast cancer research made "dimensional comparisons," in which they selectively focused on dimensions on which they appeared advantaged. For example, many older women compared themselves favorably with younger women (e.g., "That's a terrible, terrible thing for a young girl to face. It's different if you're an older woman like me."). Even women who were dying described ways in which they were luckier than other women (e.g., they were surrounded by loved ones, whereas many others were not). Although these women could have compared themselves with women who had never had breast cancer, they instead focused on dimensions on which they were superior.

Similarly, when subjects are given a choice of tasks, they tend to select ones on which their performance is not only good but also better than others' (Tesser \& Campbell, 1980; Van Knippenberg et al., 1981). Groups of boys at a summer camp were induced to compete over which group could build the best hut (Lemaine, 1974). When the researchers deliberately handicapped one group by supplying them with inadequate building materials, this group started growing a small garden, which they sought to have recognized as an alternative target of evaluation.
Generally, people appear to value dimensions on which they excel but to minimize the importance of their shortcomings (Campbell, 1986; Harter, 1986). Individuals even may redefine a dimension as less central to the self if they learn that others are superior on that dimension (Tesser, 1986; Tesser \& Campbell, 1980).

\section{Summary: How Social Comparisons Serve Goals}

How do individuals go about meeting their comparison goals in the face of an active, sometimes uncooperative environment? Clearly, comparison processes involve much more than the selection of a comparison target. Self-enhancement motives, for example, may lead to downward comparisons (or similar comparisons if one has an unfavorable characteristic), but they also may lead one to manipulate surrounding dimensions, imagine an inferior target, select a dimension on which one is advantaged, or simply avoid comparisons entirely. It is meaningful that more strategies are listed for self-enhancement than for the other comparison goals. When one's goal is self-evaluation, there is little need to manipulate one's comparisons; one may be receptive to all comparative information. As one's goal departs from accurate self-evaluation, however, one must exert more influence on the comparison process. These findings mirror those of the social cognition literature more generally; as one's goals or personal investments predominate, one is more likely to distort information strategically (Showers \& Cantor, 1985). Exerting influence on comparisons becomes especially important when the environment is uncooperative. Many of the strategies in the self-enhancement section involved situations in which the individual had been exposed to an unfavorable comparison. The Appalachian woman provides a good example.

This research also makes clear the importance of two elements in the comparison process, namely, the nature of the dimension under evaluation and the dimensions that surround the dimension under evaluation. As was mentioned earlier, Festinger (1954) did anticipate the importance of these two elements. In fact, one of the first social comparison studies manipulated both of them (Hoffman et al., 1954). However, the subsequent literature largely has failed to appreciate their influence. Both parameters act on both sides of the comparison process, influencing the effects of comparisons presented by the environment and influencing the ways in which the individual may serve his or her comparison goal.

The nature of the dimension under evaluation-its familiarity, desirability, and self-relevance-is critical, because it may determine the impact of a comparison. Comparisons on selfrelevant dimensions, for example, appear to have special impact on one's self-esteem and feelings. The dimension under evaluation also may determine whether comparisons that are forced on individuals stimulate comparison goals. Unfamiliar dimensions appear to heighten interest in understanding the dimension itself, and self-relevant dimensions seem especially likely to heighten self-enhancement motives. The nature of the dimension also influences the way the individual satisfies his or her comparison goal, because it may determine which target along the dimension will satisfy that goal. On unfamiliar dimensions, extremely dissimilar others may serve the goal of learning about the dimension under evaluation. Similar others, however, 
may make one feel better if one learns that one is high in some undesirable characteristic. On self-relevant dimensions, self-enhancement is best met not by comparing the self with similar others but by comparing the self with inferior others.

The dimensions that surround the dimension under evaluation also influence the impact of comparisons presented by the environment. Comparisons with others who are close on surrounding dimensions have special impact; favorable comparisons are especially pleasurable, and unfavorable comparisons are especially painful. Because of this, comparisons with close others seem likely to stimulate self-enhancement motives. Surrounding dimensions also assist the individual in meeting his or her aims. For example, they may assist self-evaluation because comparisons on related attributes are especially informative about the meaning of one's relative standing along the evaluation dimension.

Especially intriguing are findings that suggest that these two elements of comparison may themselves be used to serve comparison goals. After an unfavorable comparison, individuals may, for example, alter the nature of the dimension under evaluation by defining the dimension as less important (Tesser, 1986). They also may manipulate surrounding dimensions, such as by distancing themselves from a close other (Tesser, 1986).

\section{Conclusion: Implications for Social Comparison Theory}

What are the implications of the present analysis for contemporary theory in social comparison? First, it should be noted that the evidence very strongly supports Festinger's (1954) original theory in several respects. It emphasizes the importance of social comparisons in self-evaluation and social behavior. In addition, although the research challenges the similarity hypothesis in the sense that individuals often do not prefer to compare themselves with similar others, it suggests that in another sense, Festinger was correct about the importance of similar comparisons: Comparisons with people who are similar on surrounding dimensions are especially potent. Moreover, most of the need for updating the theory comes not from research involving Festinger's main interest, self-evaluation, but from research involving self-enhancement. On the other hand, the evidence also portrays the comparison process, the individual, and the social environment as sharply different from the portrait presented by the original theory and by much of subsequent research.

\section{The Complex and Manipulable Comparison Process}

The social comparison process is considerably more complex than has been recognized traditionally. Comparisons often occur on more than one dimension simultaneously, they may not involve similar targets, they are guided by a complex constellation of parameters, and they do not necessarily involve selection of a comparison target but may take a variety of forms.

Still more complexity exists in the comparison process. Masters and Keil (1987) identified many more parameters that should be taken into account in comparison research. They pointed out, for example, that many personal characteristics such as one's socialization history influence comparison evaluations. They also emphasized that the process of comparison involves multiple comparisons over time rather than single comparisons at one point in time. Two sources of complexity that Masters and Keil discussed are especially relevant to the present analysis, because they afford even more opportunities for individuals to serve their goals.

First, individuals compare themselves not only with other individuals but also with groups of people, and they compare their own groups with other groups (Goethals \& Darley, 1987; Levine \& Moreland, 1987). One may invoke group-level comparisons to serve one's goals. For example, children made comparisons that were favorable to their.own ethnic group after their group's low status was made salient (Mackie, 1984). One may invoke a group-level comparison even when a threat to self-esteem concerns a personal rather than a group-related dimension. For example, individuals who thought that they had failed on a test of creativity derogated a rival university (Cialdini \& Richardson, 1980).

A second complication that Masters and Keil (1987; see also Suls, 1986a) developed further involves the comparisons that individuals make not with others but with themselves at another time, or what Albert (1977) called "temporal comparisons." Like the capacity to alternate between individual and grouplevel comparisons, the capacity to alternate between social and temporal comparisons is likely to introduce still more flexibility in comparison processes. One may, for example, compare one's currently poor performance with one's past, even worse performance. Indeed, one may reconstruct one's past so as to see one's present circumstances more positively (Conway \& Ross, 1984).

\section{The Active Social Comparer}

Not only does the individual appear to be less rational and unbiased than Festinger (1954) portrayed, but the individual may also exert much more influence on the comparison process than social comparison researchers have assumed. Although the literature typically has emphasized that the individual is selective, it has viewed the individual's capacity to be selective as constrained by whatever comparison targets are available. However, two comparison strategies, selecting comparison dimensions and imagining comparison targets, are target free and hence present a contrasting picture of the social comparer. One need not depend on finding a comparison target who will serve one's goal; one may fabricate a target or focus on a particular dimension rather than on a specific target (Taylor et al., 1983).

Moreover, if one encounters an unfavorable comparison, one may attempt to restore one's self-esteem through selectively making what may be called postcomparison comparisons. If one learns that one is inferior on some dimension, for example, one may emphasize other dimensions in subsequent comparisons. For example, a premed major who was a subject in Salovey and Rodin's (1984) study recalled his or her thoughts on learning that another subject was superior on a test of medical science aptitude:

I couldn't help but think, "If he's such a hot-shot premed and does so well in his classes, I bet he's really just a nerd; I bet he's one of those unfriendly, antisocial weenies that hang out in the library 20 hours a day; he probably couldn't have an interesting conversation with anyone." (p. 790)

As was seen earlier, many such self-enhancing strategies may 
follow an unfavorable comparison. Most of the strategies that Tesser (1986) identified, such as reducing closeness with someone who is superior, also represent postcomparison processes (or what Masters and Keil, 1987, called compensatory comparisons).

The idea that people may make target-free comparisons, and selectively use postcomparison comparisons if an unfavorable comparison does manage to intrude, suggests that comparison information at times may reflect one's goals more than one's actual standing in relation to others. As Goethals (1986a) pointed out, individuals fabricate and ignore social reality in ways that support a particular view of themselves. Thus, social comparison often may be a process of construction; it may not always involve comparisons with other people in any usual sense (Wood et al., 1985).

\section{How "Social" is Social Comparison?}

If social comparison may be an act of construction, how social is social comparison? This emphasis on the individual's capacity to manipulate comparisons seems inconsistent with another emphasis in this review, namely, that at times comparisons are not selected, but forced, and that the self is defined by its social context. How can individuals, on the one hand, freely manipulate their comparisons and, on the other hand, be at the mercy of the surrounding social world? Clearly, both of these alternatives are too extreme to represent the typical pattern of social comparison.

Although little research in social comparison has addressed this issue, some evidence points to constraints on individuals' capacity to distort reality. Goethal's (1986a) false-consensus studies suggest that when social information is ambiguous or inconsistent, individuals may readily distort that information, but that when the information is clear cut and vivid, they are more responsive to it. Similarly, when one compares oneself with vague, nameless others, such as "the average person," one may be able to make any comparison that one desires, but when the comparison other is a specific person whom one knows, one may be less able to manipulate comparisons (Perloff $\&$ Fetzer, 1986). However, these constraints seem to be minimal; social information is likely to be ambiguous more often than not (Darley \& Goethals, 1980), and people rarely are forced to select a specific comparison target (except in the laboratory). Thus, construction processes may prevail frequently.

One must keep in mind, however, that the available research probably has vastly underestimated the role of the social environment. By focusing primarily on the selection of comparisons, the literature has largely ignored what may be the most prevalent and potent type of social comparison (Brickman \& Bulman, 1977). The comparisons that individuals do not seek but arrive unbidden-from the neighbor who takes frequent, exotic vacations or from the colleague who is awarded three large grants in one year-warrant much more theoretical and empirical attention. A promising recent analysis, for example, helps to account for how the self-concept changes in response to the social environment. Higgins, Strauman, and Klein (1986) proposed that momentary changes in one's setting or activities make one standard, of the many standards one uses in self-evaluation, more cognitively accessible than others.
In addition to imposing comparisons, the social environment is likely to awaken goals that direct the individual's social comparisons. Two examples of how it may do so were identified earlier: Comparisons on self-relevant dimensions and comparisons with others who are close on surrounding dimensions both stimulate self-enhancement motives. One's environment also is likely to stimulate more global and enduring goals. The social environment may in part determine the individual's self-concept, which leads to certain goals (Showers \& Cantor, 1985) that, in turn, guide one's comparisons with the social environment.

Research has supported aspects of this possible bidirectional relationship. The "frog pond" studies cited earlier suggest that the social environment imposes comparisons that shape the individual's self-concept. More specifically, changes in children's comparison behaviors appear to be associated with changes in their self-perceptions (Ruble \& Frey, 1987). In addition; research supports the idea that the self-concept in turn may determine one's comparisons. As children grow older, they increasingly focus their comparisons on areas that they regard as personally important (Bers \& Rodin, 1984), and adults appear to evaluate others in terms of the dimensions that they themselves value (Lewicki, 1983; Markus \& Smith, 1981). Social comparison researchers have barely begun to explore the reciprocal relationship between the social environment and the individual, an issue with which the whole field of social psychology and personality is wrestling (e.g., Bandura, 1986; Showers \& Cantor, 1985).

\section{References}

Albert, S. (1977). Temporal comparison theory. Psychological Review: 84, 485-503.

Alicke, M. D. (1985). Global self-evaluation as determined by the desirability and controllability of trait adjectives. Journal of Personality and Social Psychology, 49, 1621-1630.

Allen, V. L., \& Wilder, D. A. (1977). Social comparison, self-evaluation, and conformity to the group. In J. M. Suls \& R. L. Miller (Eds.), Social comparison processes: Theoretical and empirical perspectives (pp. 187-208). Washington, DC: Hemisphere.

Arrowood, A. J. (1978). Social comparison theory: Retrieved from neglect. Contemporary Psychology, 23, 490-491.

Arrowood, A. J., \& Friend, R. (1969). Other factors determining the choice of a comparison other Journal of Experimental Social Psychology, 5, 233-239.

Atkinson, J. W., \& Raynor, J. O. (Eds.). (1974). Motivation and achievement. Washington, DC: Hemisphere.

Bachman, J. G., \& O'Malley, P. M. (1986), Self-concepts, self-esteem, and educational experiences: The frog pond revisited (again). Journal of Personality and Social Psychology, 50, 35-46.

Bandura, A. (1986). Social foundations of thought \& action: A social cognitive theory. Englewood Cliffs, NJ: Prentice-Hall.

Berger, S. M. (1977). Social comparison, modeling, and perseverance, In J. M. Suls \& R. L. Miller (Eds.), Social comparison processes: Theoretical and empirical perspectives (pp. 209-234). Washington, DC: Hemisphere.

Bers, S. A., \& Rodin, J. (1984). Social-comparison jealousy: A developmental and motivational study. Journal of Personality and Social Psychology, 47, 766-779.

Brickman, P., \& Berman, J. J. (1971). Effects of performance expectancy and outcome certainty on interest in social comparison. Journal of Experimental Social Psychology, 7, 600-609. 
Brickman, P., \& Bulman, R. J. (1977). Pleasure and pain in social comparison. In J. M. Suls \& R. L. Miller (Eds.), Social comparison processes: Theoretical and empirical perspectives (pp. 149-186). Washington, DC: Hemisphere.

Brown, J. D. (1986). Evaluations of self and others: Self-enhancement biases in social judgments. Social Cognition, 4, 353-376.

Campbell, J. D. (1986). Similarity and uniqueness: The effects of attribute type, relevance, and individual differences in self-esteem and depression. Journal of Personality and Social Psychology, 50, 281294.

Carlson, C. R., \& Masters, J. C. (1986). Inoculation by emotion: Effects of positive emotional states on children's reactions to social comparison. Developmental Psychology, 22, 760-765.

Cash, T. F., Cash, D. W., \& Butters, J. W. (1983). "Mirror, mirror, on the wall . . . ?": Contrast effects and self-evaluations of physical attractiveness. Personality and Social Psychology Bulletin, 9, 351-358.

Cialdini R. B., \& Richardson, K. D. (1980). Two indirect tactics of impression management: Basking and blasting. Journal of Personality and Social Psychology, 39, 406-415.

Conway, M., \& Ross, M. (1984), Getting what you want by revising what you had. Journal of Personality and Social Psychology, 47, 738748.

Crocker, J., \& Gallo, L. (1985, August). The self-enhancing effect of downward comparison. Paper presented at the meeting of the American Psychological Association, Los Angeles, CA.

Crocker, J., Thompson, L. L., McGraw, K. M., \& Ingerman, C. (1987). Downward comparison prejudice and evaluations of others: Effects of self-esteem and threat. Journal of Personality and Social Psychology, 52, 907-916.

Crosby, F. (1976). A model of egoistical relative deprivation. Psychological Review, 83, 85-113.

Dakin, S., \& Arrowood, A. J. (1981). The social comparison of ability. Human Relations, 34, 89-109.

Darley, J. M., \& Goethals, G. R. (1980). People's analyses of the causes of ability-linked performances. In L. Berkowitz (Ed.), Advances in experimental social psychology (pp. 1-37). New York: Academic Press.

Davis, J. A. (1966). The campus as a frog pond: An application of the theory of relative deprivation to career decisions of college men. American Journal of Sociology, 72, 17-31.

Deutsch, M., \& Krauss, R. M. (1965). Theories in social psychology. New York: Basic Books.

Diener, E. (1984). Subjective well-being. Psychological Bulletin, 95, 542-575.

Feldman, N. S., \& Ruble, D. N. (1977). Awareness of social comparison interest and motivations: A developmental study. Journal of Educational Psychology, 69, 579-585.

Feldman, N. S., \& Ruble, D. N. (1981). Social comparison strategies: Dimensions offered and options taken. Personality and Social Psychology Bulletin, 7, 11-16.

Festinger, L. (1954). A theory of social comparison processes. Human Relations, 7, 117-140.

Fisher, J., Nadler, A., \& Whitcher-Alagna, S. (1982). Recipient reactions to aid. Psychological Bulletin, 91, 27-54.

France-Kaatrude, A., \& Smith, W. P. (1985). Social comparison, task motivation, and the development of self-evaluative standards in children. Developmental Psychology, 21, 1080-1089.

Frey, K. S., \& Ruble, D. N. (1985). What children say when the teacher is not around: Conflicting goals in social comparison and performance assessment in the classroom. Journal of Personality and Social Psychology, 48, 550-562.

Friend, R. M., \& Gilbert, J. (1973). Threat and fear of negative evaluation as determinants of locus of social comparison. Journal of Personality, 41, 328-340.
Fromkin, H. L. (1972). Feelings of interpersonal undistinctiveness: An unpleasant affective state. Journal of Experimental Research in Personality, 6, 178-185.

Gastorf, J. W., \& Suls, J. (1978). Performance evaluation via social comparison: Performance similarity versus related attribute similarity. Social Psychology, 41, 297-305.

Gastorf, J. W., Suls, J., \& Lawhon, J. (1978), Opponent choices of below average performers. Bulletin of the Psychonomic Society, 12, 217220.

Gastorf, J. W., Suls, J., \& Sanders, G. S. (1980). Type A coronary-prone behavior pattern and social facilitation. Journal of Personality and Social Psychology, 38, 773-780.

Gibbons, F. X. (1985). A social-psychological perspective on developmental disabilities. Journal of Social and Clinical Psychology, 3, 391404.

Gibbons, F. X. (1986). Social comparison and depression: Company's effect on misery. Journal of Personality and Social Psychology, 51, 140-148.

Goethals, G. R. (1986a). Fabricating and ignoring social reality: Selfserving estimates of consensus. In J. M. Olson, C. P. Herman, \& M. P. Zanna (Eds.), Relative deprivation and social comparison: The Ontario Symposium (Vol. 4, pp. 135-158). Hillsdale, NJ: Erlbaum.

Goethals, G. R. (1986b). Social comparison theory: Psychology from the lost and found. Personality and Social Psychological Bulletin, 12, 261-278.

Goethals, G. R., \& Darley, J. M. (1977). Social comparison theory: An attributional approach:' In J. M. Suls \& R. L. Miller (Eds.), Social comparison processes: Theoretical and empirical perspectives (pp. 259-278). Washington, DC: Hemisphere.

Goethals, G. R., \& Darley, J. M. (1987). Social comparison theory: Selfevaluation and group life. In B. Mullen \& G. R. Goethals (Eds.), Theories of group behavior (pp. 21-47). New York: Springer-Verlag.

Gruder, C. L. (1971). Deter minants of social comparison choices. Journal of Experimental Social Psychology, 7, 473-489.

Gruder, C. L. (1977). Choice of comparison persons in evaluating oneself. In J. M. Suls \& R. L. Miller (Eds.), Social comparison processes. Theoretical and empirical perspectives (pp. 21-41). Washington, DC: Hemisphere.

Gruder, C. L., Korth, B., Dichtel, M., \& Glos, B. (1975). Uncertainty and social comparison. Journal of Research in Personality, 9, 85-95.

Guiot, J. M. (1978). Some comments on social comparison processes. Journal for the Theory of Social Behaviour, 8, 29-43.

Hakmiller, K. L. (1966a) Need for self-evaluation, perceived similarity and comparison choice. Journal of Experimental Social Psychology, Supplement 1, 49-54.

Hakmiller, K. L. (1966b). Threat as a determinant of downward comparison. Journal of Experimental Social Psychology, Supplement 1, 32-39.

Harter, S. (1985). Commentary: On the need for a developmental perspective in understanding child and adolescent disorders. Journal of Social and Clinical Psychology, 3, 484-499.

Harter, S. (1986). Processes underlying the construction, maintenance, and enhancement of the self-concept in children. In J. Suls \& A. G. Greenwald (Eds.), Psychological perspectives on the self (Vol. 3, pp. 137-181). Hillsdale, NJ: Erlbaum.

Heider, F. (1958). The psychology of interpersonal relations. New York: Wiley.

Higgins, E. T., Strauman, T., \& Klein, R. (1986). Standards and the process of self-evaluation: Multiple affects from multiple stages. In R. M. Sorrentino \& E. T. Higgins (Eds.), Handbook of motivation and cognition: Foundations of social behavior (pp. 23-63). New York: Guilford.

Hoffman, P. J., Festinger, L., \& Lawrence, D. H. (1954). Tendencies 
toward group comparability in competitive bargaining. Human Relations, 7, 141-159.

Jones, E. E., \& Gerard, H. B. (1967). Foundations of social psychology. New York: Wiley.

Latané, B. (1966). Studies in social comparison: Introduction and overview. Journal of Experimental Social Psychology, Supplement 1, 1-5.

Lemaine, G. (1974). Social differentiation and social originality. European Journal of Social Psychology, 4, 17-52.

Lemyre, L., \& Smith, P. M. (1985). Intergroup discrimination and selfesteem in the minimal intergroup paradigm. Journal of Personality and Social Psychology, 49, 660-670.

Levine, J. M., \& Green, S. M. (1984). Acquisition of relative performance information: The roles of intrapersonal and interpersonal comparison. Personality and Social Psychology Bulletin, 10, 385393.

Levine, J. M., Moreland, R. L. (1987). Social comparison and outcome evaluation in group contexts. In J. C. Masters \& W. P. Smith (Eds.), Social comparison, social justice, and relative deprivation: Theoretical, empirical, and policy perspectives (pp. 105-127). Hillsdale, NJ: Erlbaum.

Lewicki, P. (1983). Self-image bias in person perception. Journal of Personality and Social Psychology, 45, 384-393.

Mackie, D. (1984). Social comparison in high- and low-status groups. Journal of Cross-Cultural Psychology, 15, 379-398.

Major, B., \& Forcey, B. (1985). Social comparisons and pay evaluations: Preferences for same-sex and same-job wage comparisons. Journal of Experimental Social Psychology, 21, 393-405.

Marks, G. (1984). Thinking one's abilities are unique and one's opinions are common. Personality and Social Psychology Bulletin, 10, 203-208.

Marks, G., \& Miller, N. (1987). Ten years of research on the false-consensus effect: An empirical and theoretical review. Psychological Bulletin, 102, 72-90.

Markus, H. (1977). Self-schemata and processing information about the self. Journal of Personality and Social Psychology, 35, 63-78.

Markus, H., \& Smith, J. (1981). The influence of self-schemata on the perception of others. In N. Cantor \& J. Kihlstrom (Eds.), Personality, cognition, and social interaction (pp. 233-262). Hillsdale, NJ: Er1baum.

Marsh, H. W., Parker; J. W. (1984). Determinants of student selfconcept: Is it better to be a relatively large fish in a small pond even if you don't learn to swim as well? Journal of Personality and Social Psychology, 47, 213-231.

Martin, J. (1986). The tolerance of injustice. In J. M. Olson, C. P. Herman, \& M. P. Zanna (Eds.), Relative deprivation and social comparison: The Ontario Symposium (Vol. 4, pp. 217-242). Hillsdale, NJ: Erlbaum.

Masters, J. C., \& Keil, L. J. (1987). Generic comparison processes in human judgement and behavior. In J. C. Masters \& W. P. Smith (Eds.), Social comparison, social justice, and relative deprivation: Theoretical, empirical, and policy perspectives (pp. 11-54). Hillsdale, NJ: Erlbaum.

Masters, J. C., \& Smith, W. P. (Eds.). (1987). Social comparison, social justice, and relative deprivation: Theoretical, empirical, and policy perspectives. Hillsdale, NJ: Erlbaum.

Matthews, K. A., \& Siegel, J. M. (1983). Type A behaviors by children, social comparison, and standards for self-evaluation. Developmental Psychology, 19, 135-140.

McGuire, W. J., \& Padawer-Singer, A. (1976). Trait salience in the spontaneous self-concept. Journal of Personality and Social Psychology, 33, 743-754.

Menaghan, E. (1982). Measuring coping effectiveness: A panel analysis of marital problems and coping efforts. Journal of Health and Social Behavior, 23, 220-234.
Messé, L. A., \& Watts, B. L. (1983). Complex nature of the sense of fairness: Internal standards and social comparison as bases for reward evaluations. Journal of Personality and Social Psychology, 46, 684693.

Mettee, D. R., \& Smith, G. (1977). Social comparison and interpersonal attraction: The case for dissimilarity. 'In J. M. Suls \& R. L. Miller (Eds.), Social comparison processes: Theoretical and empirical perspectives (pp. 69-101). Washington, DC: Hemisphere.

Miller, C. T. (1982). The role of performance-related similarity in social comparison of abilities: A test of the related attributes hypothesis. Journal of Experimental Social Psychology, 18, 513-523.

Miller, C. T. (1984). Self-schemas, gender, and social comparison: A clarification of the related attributes hypothesis. Journal of Personality and Social Psychology, 46, 1222-1228.

Miller, D. T., Turnbull, W., McFarland, C. (1988). Particularistic and universalistic evaluation in the social comparison process. Journal of Personality and Social Psychology, 55, 908-917.

Miller, R. L., \& Suls, J. M. (1977). Affiliation preferences as a function of attitude and ability similarity. In J. M. Suls \& R. L. Miller (Eds.), Social comparison processes: Theoretical and empirical perspectives (pp. 103-123). Washington, DC: Hemisphere.

Morse, S., \& Gergen, K. J. (1970). Social comparison, self-consistency, and the concept of self. Journal of Personality and Social Psychology, $16,148-156$.

Nadler, A., Fisher, J. D., \& Streufert, S. (1976). When helping hurts: Effects of donor-recipient similarity and recipient self-esteem on reactions to aid. Journal of Personality, 44, 392-409.

Nosanchuk, T. A., \& Erickson, B. H. (1985). How high is up? Calibrating social comparison in the real world. Journal of Personality and Social Psychology, 48, 624-634.

Olson, J. M., Herman, C. P., \& Zanna; M. P. (Eds.). (1986). Relative deprivation and social comparison: The Ontario Symposium (Vol. 4). Hillsdale, NJ: Erlbaum.

Pearlin, L. I., Lieberman, M. A., Menaghan, E. G., \& Mullan, J. T. (1981). The stress process. Journal of Health and Social Behavior, 22, 337-356.

Pearlin, L. I., \& Schooler, C. (1978). The structure of coping. Journal of Health and Social Behavior, 19, 2-21.

Perloff, L. S., \& Fetzer, B. K. (1986). Self-other judgments and perceived vulnerability to victimization. Journal of Personality and Social Psychology, 50, 502-510.

Pettigrew, T. F. (1967). Social evaluation theory: Convergences and applications. In D. Levine (Ed.), Nebraska Symposium on Motivation, (Vol. 15, pp. 241-311). Lincoln: University of Nebraska Press.

Pleban, R., \& Tesser, A. (1981). The effects of relevance and quality of another's performance on interpersonal closeness. Social Psychology Quarterly, 44, 278-285.

Pyszczynski, T., Greenberg, J., \& LaPrelle, J. (1985). Social comparison after success and failure: Biased search for information consistent with a self-serving conclusion. Journal of Experimental Social Psychology, 21, 195-211.

Radloff, R. (1966). Social comparison and ability evaluation. Journal of Experimental Social Psychology, Supplement 1, 6-26.

Radloff, R., \& Bard, L. (1966). A social comparison bibliography. Journal of Experimental Social Psychology, Supplement 1, 111-115.

Raynor, J. O., \& McFarlin, D. B. (1986). Motivation and the self-system. In R. M. Sorrentino \& E. T. Higgins (Eds.), Handbook of motivation and cognition: Foundations of social behavior (pp. 315-349). New York: Guilford.

Ross, L., Greene, D., \& House, P. (1977). The "false consensus effect": An egocentric bias in social perception and attribution processes. Journal of Experimental Social Psychology, 13, 279-301.

Ruble, D. N. (1983). The development of social comparison processes and their role in achievement-related self-socialization. In E. T. Hig- 
gins, D. N. Ruble, \& W. W. Hartup (Eds.), Social cognition and social development: $A$ sociocultural perspective (pp. 134-157). Cambridge, England: Cambridge University Press.

Ruble, D. N., Feldman, N. S., \& Boggiano, A. K. (1976) Social comparison between young children in achievement situations. Developmental Psychology, 12, 192-197.

Ruble, D. N., \& Frey, K. S. (1987). Social comparison and self-evaluation in the classroom: Developmental changes in knowledge and function. In J. C. Masters \& W. P. Smith (Eds.), Social comparison, social justice, and relative deprivation: Theoretical, empirical, and policy perspectives (pp. 81-104). Hillsdale, NJ: Erlbaum.

Sackeim, H. A. (1983). Self-deception, self-esteem, and depression: The adaptive value of lying to oneself. In J. Masling (Ed.), Empirical studies of psychoanalytical theories (Vol. 1, pp. 101-157). Hillsdale, NJ: The Analytic Press.

Salovey, P., \& Rodin, J. (1984). Some antecedents and consequences of social-comparison jealousy. Journal of Personality and Social Psychology, 47, 780-792.

Samuel, W. (1973). On clarifying some interpretations of social comparison theory. Joumal of Experimental Social Psychology, 9, 450-465.

Sanders, G. S. (1982a). Social comparison as a basis for evaluating others. Journal of Research in Personality, 16, 21-31.

Sanders, G. S. (1982b). The effects of social comparison on ability evaluations. European Journal of Social Psychology, 12, 63-74.

Sanders, G. S., Gastorf, J. W., \& Mullen, B. (1979). Selectivity in the use of social comparison information. Personality and Social Psychology Bulletin, 5, 377-380.

Sanders, G. S., \& Mullen, B. (1983). Accuracy in perceptions of consensus: Differential tendencies of people with majority and minority positions. European Journal of Social Psychology, 13, 57-70.

Scheier, M., \& Carver, C. (1983). Self-directed attention and the comparison of self with standards! Journal of Experimental Social Psychology, 19, 205-222.

Schulz, R., \& Decker, S. (1985). Long-term adjustment to physical disability: The role of social support, perceived control, and self-blame. Journal of Personality and Social Psychology, 48, 1162-1172.

Seta, J. (1982). The impact of comparison processes on coactors' task performance. Journal of Personality and Social Psychology, 42, 281291.

Shaffer, P. (1980). Amadeus. New York: Samuel French.

Sherman, S. J., Presson, C. C., \& Chassin, L. (1984). Mechanisms underlying the false consensus effect: The special role of threats to the self. Personality and Social Psychology Bulletin, 10, 127-138.

Showers, C., \& Cantor, N. (1985). Social cognition: A look at motivated strategies. Annual Review of Psychology, 36, 275-305.

Singer, J. E. (1966). Social comparison-Progress and issues. Journal of Experimental Social Psychology, Supplement 1, 103-110.

Smith, R. H., \& Insko, C. A. (1987). Social comparison choice during ability evaluation: The effects of comparison publicity, performance feedback, and self-esteem. Personality and Social Psychology Bulletin, 13, 111-122.

Smith, W. P., Davidson, E. S., \& France, A. (1987). Social comparison and achievement evaluation in children. In J. C. Masters \& W. P. Smith (Eds.), Social comparison, social justice, and relative deprivation: Theoretical, empirical, and policy perspectives (pp. 55-79). Hillsdale, NJ: Erlbaum.

Strang, L., Smith, M. D., \& Rogers, C. M. (1978). Social comparison, multiple reference groups and the self-concepts of academically handicapped children before and after mainstreaming. Journal of Educational Psychology, 70, 487-497.

Suls, J. M. (1977). Social comparison theory and research: An overview from 1954. In J. M. Suls \& R. L. Miller (Eds.), Social comparison processes: Theoretical and empirical perspectives (pp. 1-19). Washington, DC: Hemisphere.
Suls, J. (1986a). Comparison processes in relative deprivation: A lifespan analysis. In J. M. Olson, C. P. Herman, \& M. P. Zanna (Eds.), Relative deprivation and social comparison: The Ontario Symposium, (Vol. 4, pp. 95-116). Hillsdale, NJ: Erlbaum.

Suls, J. (1986b). Notes on the occasion of social comparison theory's thirtieth birthday. Personality and Social Psychology Bulletin, 12, 289-296.

Suls, J., Gaes, G., \& Gastorf, J. (1979). Evaluating a sex-related ability: Comparison with same-, opposite-, and combined-sex norms. Journal of Research in Personality, 13, 294-304.

Suls, J. M., Gastorf, J., \& Lawhon, J. (1978). Social comparison choices for evaluating a sex- and age-related ability. Personality and Social Psychology Bulletin, 4, 102-105.

Suls, J. M., Miller, R. L. (Eds.). (1977): Social comparison processes: Theoretical and empirical perspectives. Washington, DC: Hemisphere.

Suls, J. M., \& Tesch, F. (1978). Students' preferences for information about their test performance: A social comparison study. Journal of Applied Social Psychology, 8, 189-197.

Suls; J., \& Wan, C. K. (1987). In search of the false-uniqueness phenomenon: Fear and estimates of social consensus. Journal of Personality and Social Psychology, 52, 211-217.

Tajfel, H., \& Turner, J. C. (1979). An integrative theory of intergroup conflict. In W. G. Austin \& S. Worchel (Eds.), The social psychology of intergroup relations (pp. 33-48). Chicago: Nelson-Hall.

Taylor, S. E., \& Brown, J. (1988). Illusion and well-being: A social psychological perspective on mental health. Psychological Bulletin, 103, 193-210.

Taylor, S. E., Wood, J. V., \& Lichtman, R. R. (1983), It could be worse: Selective evaluation as a response to victimization. Journal of Social Issues, 39, 19-40.

Tesser, A. (1980). Self-esteem maintenance in family dynamics. Journal of Personality and Social Psychology, 39, 77-91.

Tesser, A. (1986). Some effects of self-evaluation maintenance on cognition and action. In R. M. Sorrentino \& E. T. Higgins (Eds.), Handbook of motivation and cognition: Foundations of social behavior (pp. 435-464). New York: Guilford.

Tesser, A., \& Campbell, J. (1980). Self-definition: The impact of the relative performance and similarity of others. Social Psychology Quarterly, 43, 341-347.

Tesser, A., \& Campbell, J. (1982). Self-evaluation maintenance and the perception of friends and strangers. Journal of Personality, 50, 261279.

Tesser, A., \& Campbell, J. (1985). A self-evaluation maintenance model of student motivation. In C. Ames \& R. Ames (Eds.), Research on motivation in education: The classroom milieu (pp. 217-247). New York: Academic Press.

Tesser, A., Millar, M., \& Moore, J. (1988). Some affective consequences of social comparison and reflection processes: The pain and pleasure of being close. Journal of Personality and Social Psychology, 54, 4961.

Tesser, A., \& Smith, J. (1980). Some effects of friendship and task relevance on helping: You don't always help the one you like. Journal of Experimental Social Psychology, 16, 583-590.

Thornton, D. A., \& Arrowood; A. J. (1966). Self-evaluation, self-enhancement, and the locus of social comparison. Journal of Experimental Social Psychology, Supplement 1, 40-48.

Trope, Y. (1979). Uncertainty-reducing properties of achievement tasks. Journal of Personality and Social Psychology, 37, 1505-1518.

Trope, Y. (1986). Self-enhancement and self-assessment in achievement behavior. In R. M. Sorrentino \& E. T. Higgins (Eds.), Handbook of motivation and cognition: Foundations of social behavior (pp. 350378). New York: Guilford. 
Updike, J. (1985, September 2). Personal history: At war with my skin. New Yorker, 61, 39-57.

Van Knippenberg, A., Wilke, H., \& de Vries, N. K. (1981). Social comparison on two dimensions. European Journal of Social Psychology, $11,267-283$.

Wheeler, L. (1966). Motivation as a determinant of upward comparison. Journal of Experimental Social Psychology, Supplement 1, 2731.

Wheeler L., \& Koestner, R. (1984). Performance evaluation: On choosing to know the related attributes of others when we know their performance. Journal of Experimental Social Psychology, 20, 263-271.

Wheeler, L., Koestner, R., \& Driver, R. E. (1982). Related attributes in the choice of comparison others: It's there, but it isn't all there is. Journal of Experimental Social Psychology, 18, 489-500.

Wheeler, L., Shaver, K. G., Jones, R. A., Goethals, G. R., Cooper, J., Robinson, J. E., Gruder, C. L., \& Butzine, K. W. (1969). Factors determining the choice of a comparison other. Journal of Experimental Social Psychology, 5, 219-232.

Wheeler, L., \& Zuckerman, M. (1977). Commentary. In J. M. Suls \& R. L. Miller (Eds.), Social comparison processes: Theoretical and empirical perspectives (pp. 335-357). Washington, DC: Hemisphere.

Wills, T. A. (1981). Downward comparison principles in social psychology: Psychological Bulletin, 90, 245-271.
Wilson, S. R. (1973). Ability evaluation and self-evaluation as types of social comparison. Sociometry, 36, 600-607.

Wilson, S. R., \& Benner, L. A. (1971). The effects of self-esteem and situation upon comparison choices during ability evaluation. Sociometry, 34, 381-397.

Wood, J. V. (1989). Methods in social comparison research. Manuscript submitted for publication.

Wood, J. V., \& Taylor, K. L. (in press). Serving self-relevant goals through social comparison. In J. Suls \& T. A. Wills (Eds.), Social comparison: Contemporary theory and research. Hillsdale, NJ: Erlbaum.

Wood, J. V., Taylor, S. E., \& Lichtman, R. R. (1982, August). Social comparison processes in serious illness. Paper presented at the annual meeting of the American Psychological Association, Washington, DC.

Wood, J. V., Taylor; S. E., \& Lichtman, R. R. (1985). Social comparison in adjustment to breast cancer: Journal of Personality and Social Psychology, 49, 1169-1183.

Zanna, M. P., Goethals; G. R. \& Hill, J. F. (1975). Evaluating a sexrelated ability: Social comparison with similar others and standard setters. Journal of Experimental Social Psychology, $11,86-93$.

Received January 28, 1988

Revision received July 5, 1988

Accepted October 14, 1988

\section{APA Convention "Call for Programs"}

The "Call for Programs" for the 1990 APA annual convention will be included in the October issue of the APA Monitor. The 1990 convention will be held in Boston, Massachusetts, from August 10 through August 14. Deadline for submission of program and presentation proposals is December 15, 1989. This earlier deadline is required because many university and college campuses will close for the holidays in mid-December and because the convention is in midAugust. Additional copies of the "Call" will be available from the APA Convention Office in October. 